\title{
Exposición Al Material Particulado En Las Áreas De Preparación De Material Abrasivo De Una Empresa En El Parque Industrial De Riobamba
}

\author{
Diego Fernando Mayorga Pérez. \\ Edwin Fernando Viteri Nuñez \\ María Verónica Albuja Landi \\ Javier Enrique Orna Chávez. \\ Otto Fernando Balseca Sampedro \\ Jorge Isaías Caicedo Reyes
}

Docente- Investigador de la Facultad de Mecánica

Escuela Superior Politécnica de Chimborazo - Ecuador

Catalina Margarita Verdugo Bernal

Docente- Investigador de la Facultad de Recursos Naturales

Escuela Superior Politécnica de Chimborazo - Ecuador

doi: 10.19044/esj.2017.v13n6p224 ～URL:http://dx.doi.org/10.19044/esj.2017.v13n6p224

\begin{abstract}
In this research, a study of the determinants of risk and exposure on a particular matter was done in preparation for the areas of abrasive material.

Qualification of chemical risks (inorganic powder) using the matrix triple irrigation was performed. In addition, the dust concentration in each position was evaluated using the rules NIOSH 0500 (total dust) and NIOSH 0600 (respirable dust) by statistical criteria NIOSH. Thus, their results are based on the gravimetric method. A sanitary survey to determine the relationship between the study variables with the powder was also performed.

After examining the sampling points, 5 points was obtained with overexposure. As a result, a letter of commitment was made with corrective actions. It also re-monitors those exposed points overexposure resulting in a point (primary crusher). However, this works one to two times per month for 4 hours. As a result, no longer exposure would make production workers rotate jobs.

Additional corrective actions, to further reduce exposure to dust extractor main advantage powders, were proposed. This, however, results in the generation of optimal environment for workers.
\end{abstract}


Keywords: Total Dust, inhalable dust, breathable dust, PM 10, PM 2.5, gravimetry, NIOSH

\section{Resumen}

En el presente trabajo de investigación se realiza un estudio de los determinantes de riesgo y exposición al material particulado en las en las áreas de preparación del material abrasivo.

Se realiza una cualificación del riesgo químico (polvo inorgánico) usando la matriz de riegos de triple, además se evaluó la concentración de polvo en cada puesto utilizando las normas NIOSH 0500 (polvo total) y NIOSH 0600 (polvo respirable) por medio del criterio estadístico NIOSH cuyos resultados están en función del método gravimétrico. También se realizó una encuesta higiénica para determinar la relación de las variables de estudio con el polvo.

Una vez evaluados los puntos de muestreo se obtuvo 5 puntos con sobreexposición por lo que se realizó un acta de compromiso con acciones correctivas y se volvieron a monitorear dichos puntos expuestos resultando un punto con sobreexposición (Trituradora primaria) sin embargo esta funciona de una a dos veces por mes por 4 horas por lo que no se tendría exposición ya que además los trabajadores de producción rotan en los puestos de trabajo.

Se propuso acciones correctivas adicionales para reducir más la exposición al polvo aprovechando el extractor de polvos principal, generándose un ambiente óptimo para los trabajadores.

Palabras claves: Polvo total, Polvo inhalable, Polvo respirable, PM 10, PM 2.5, Gravimetría, NIOSH

\section{Introducción}

La mayor cantidad de material abrasivo que produce la empresa es enviado a la industria petrolera, la cual solicita que el material contenga un determinado porcentaje de sílice. Para determinar dicho contenido, la empresa se realizó un Informe Técnico en julio de 2013 en el que se expresa que la empresa no produce sílice libre cristalizada, ya que ésta se obtiene bajo condiciones de tratamiento térmico. Esta información se corrobora con Schiavon, Redondo \& Yoshida, (2007) y, considerando además que para obtener este material abrasivo se requiere de una serie de procesos de trituración de una roca llamada basalto cuya estructura es dura de acuerdo a Bossi, Ortiz, Caggiano; Olivera, (2011), ello permite que se rompa fácilmente, además debido a su forma angular permite que tenga mejores incrustaciones en las escorias a ser eliminadas por lo que durante la trituración se genera polvo en las diferentes áreas de preparación 
La empresa realizo un informe técnico, (2013), el estudio, no habría riesgo para los trabajadores por estar expuestos a este tipo de polvo generado en la actividad desde el punto de vista físico (por tamaño de partícula) porque el material abrasivo que comercializa la empresa tiene un tamaño que oscila entre 500 y $2000 \mu \mathrm{m}(0,5 \mathrm{~mm}$ a $2 \mathrm{~mm})$ o químico (no contiene sílice). Sin embargo, en el mismo recomienda la realización de un estudio en el que se determine el polvo total y la fracción respirable para saber si los trabajadores están expuestos realmente.

La afirmación de la ausencia de sílice justificada por el tratamiento empleado en la empresa se corroboró posteriormente a través de un análisis químico realizado por el LABCESTTA de la Escuela Superior Politécnica de Chimborazo en el que se determinó que a la salida de la zaranda la cantidad de sílice es de $0,0031 \%$.

Como se determina en diferente trabajos (Netse, s.f.; Simancas, et.al., 2011; Cortez, 2007; Instituto Nacional de Seguridad e Higiene en el Trabajo, INSHT, 2013; Reglamento Técnico Polvo de Ślice, 2008.), solo si la cantidad de sílice es igual o superior al 1\% se debe abordar el estudio de la exposición a las partículas de esta composición química. Como el porcentaje de sílice es menor al $1 \%$ en el material tratado, la empresa pidió que se realizara un estudio de la determinación del polvo total y del polvo en la fracción respirable para determinar la exposición de los trabajadores.

Harari, R. (2007) desarrolló un estudio con el fin de determinar la exposición a polvo mineral y sus efectos sobre la función respiratoria en los pobladores de Tanlahuan y de Atacuchu (Ecuador). En las mediciones ambientales realizadas se mostró que las concentraciones de material particulado superan la Guía de Calidad de Aire de la Organización Mundial de la Salud.

Querol expuso que a pesar de que la mayor parte de las emisiones de materia mineral son de origen natural, también es necesario considerar la existencia de fuentes de origen antropogénico. Así, actividades como la construcción, la minería o la fabricación de cerámicas o cementos generan partículas minerales, ya sea a través de la propia actividad o durante los procesos de manipulación y transporte de materias primas (Querol, et. al., 2001 citado en Querol, 2008)

La OMS publicó una guía en el 2005 donde se considera que el aire limpio es un requisito para la salud y el bienestar de los trabajadores y refiere que la mayoría de los estudios epidemiológicos utilizan el PM10 como indicador de la exposición. El PM10 son las partículas que entran al sistema respiratorio e incluye tamaños entre 2.5 y $10 \mu \mathrm{m}$, las mismas que son generadas por medio de procesos mecánicos. El PM2.5 son partículas finas de menos de $2.5 \mu \mathrm{m}$ y se considera que contribuyen a los efectos en la salud y que se generan sobre todo por proceso de combustión. 
Esta guía da los parámetros de exposición al material particulado sea por un año o por día.

En el Reglamento técnico de polvo de sílice (2008) se estandariza la forma de realizar los estudios de exposición al polvo y análisis de sílice de las muestras obtenidas. Además describe cómo realizar las determinaciones del polvo suspendido en los ambientes de trabajo y el método que sirve para la recolección del polvo total y polvo de la fracción respirable. En el Reglamento se especifican equipos, materiales y procedimientos para la toma de muestras, así como los métodos de control del polvo que se pueden aplicar en las empresas. Se realizan recomendaciones para seleccionar la estrategia de muestreo según el tiempo de muestreo o según la ubicación del sistema de muestreo, cantidad de muestra y sobre la determinación de los trabajadores a muestrear.

Los equipos y accesorios usados en el muestreo son: bombas de muestreo, medios de retención como filtro de recolección, soporte del filtro, portafiltro o cassette, ciclón seleccionador del tamaño, equipo de secada y pesaje, equipo para calibración y cargadores.

Con respecto a la toma de muestras se especifica la ubicación de la bomba en el operario, el manejo del portafiltro, y en relación a la recolección de la muestra se debe considerar que cada lote de filtros muestreados se debe acompañar de un filtro blanco e identificar cada muestra.

Netse (s.f.) realizó un estudio para cuantificar la cantidad de polvo no clasificado total definido como las "fracciones de partículas inhalables y torácicas que entran en el compartimiento superior del sistema respiratorio y aquellas que introducidas por la boca alcanzan el pulmón y región de intercambio gaseoso" (Reglamento Técnico del Sílice, 2008, p.16) y polvo no clasificado en fracción respirable que "se refiere al tamaño de las partículas menores o iguales a 10 micras que pasan la región nasofaríngea $y$ traqueobronquial para depositarse en la región alveolar o región de intercambio gaseoso" (Reglamento Técnico del Sílice, 2008, p.37); así como también muestras de fracción respirable que contenían sílice libre. El estudio se desarrolló en el sector de la construcción en Chile debido al crecimiento del mismo en los últimos años. La utilización de herramientas eléctricas a altas revoluciones ha aumentado la productividad en este sector, pero a su vez han provocado un aumento de la concentración de polvo en los puestos de trabajo y por ende la exposición de los trabajadores a este material.

En los resultados obtenidos se observó que en los puestos donde se utilizaban herramientas eléctricas se superaron los límites establecidos por la norma vigente tanto para la sílice como para el polvo total y fracción respirable establecidos en el art. 66 del Decreto Supremo Nro. 594 del ministerio de Salud (Asociación Chilena de Seguridad, ACHS. 2001). 
Simancas, et. al. (2011) presentaron una Guía de Buenas Prácticas para el control del polvo y de la sílice cristalina en el sector de ladrillos y tejas de arcilla cocida en España. En esta guía se realiza una descripción de este sector así como de su proceso productivo, además se detallan los niveles habituales de sílice cristalina en ciertos minerales:

En el documento se analizaron las fuentes de emisión del polvo así como de la sílice. Describieron los puestos a evaluar y se establecieron estrategias de muestreo en la que la toma de muestras de polvo se realizó a través de una bomba de aspiración, con el ciclón y el filtro. En el procedimiento de muestreo se describe desde la colocación de la bomba personal hasta el análisis de las muestras en el laboratorio, para posteriormente realizar un informe final y determinar si la exposición es aceptable, inaceptable o existe una indeterminación.

Los resultados obtenidos permitieron el establecimiento de las fases de prevención tanto desde el punto de vista técnico como médico.

Falagán, Alonso, Piñol y Fernández (2000) entienden por estrategia "la forma en que tiene lugar el desarrollo operativo de un proceso de toma de muestras" (p.76), indica el Elección del método de muestreo, la selección de los puestos de trabajo, Número de muestras a tomar y la duración de cada muestra.

\section{Metodología}

La metodología para la captación de muestras está basado en Falagán et al. (2000), y en el Reglamento Técnico Polvo de Sílice. (2008) como se describe a continuación.

Primeramente se define que es Proceso Productivo: "es un suceso o una serie de sucesos físicos y actividades en que participa el ser humano, sumando los activos, con la intención de transformar recursos (insumos) en productos (resultados)" (Alessio, 2002, p.28). 
Gráfico No. 01. Ciclo productivo del material abrasivo

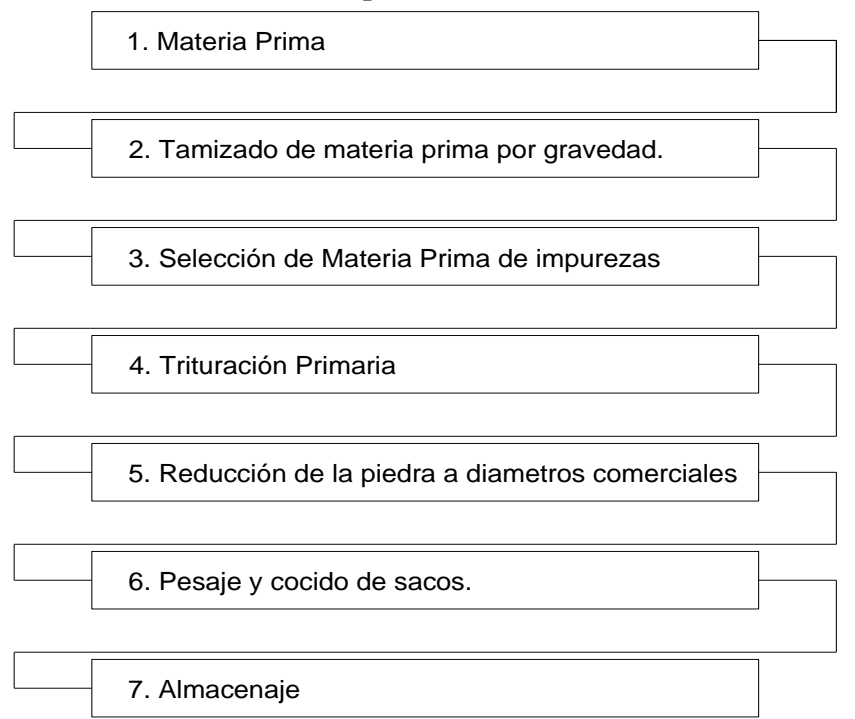

Fuente: Investigación de campo, 2015

Realizado por: Investigadores

Alessio (2002) indica que ciclo tecnológico es el cambio físico de la materia prima por medio de manufactura y conversión para lo cual se requiere de cierta tecnología.

Gráfico No. 02. Ciclo tecnológico del material abrasivo

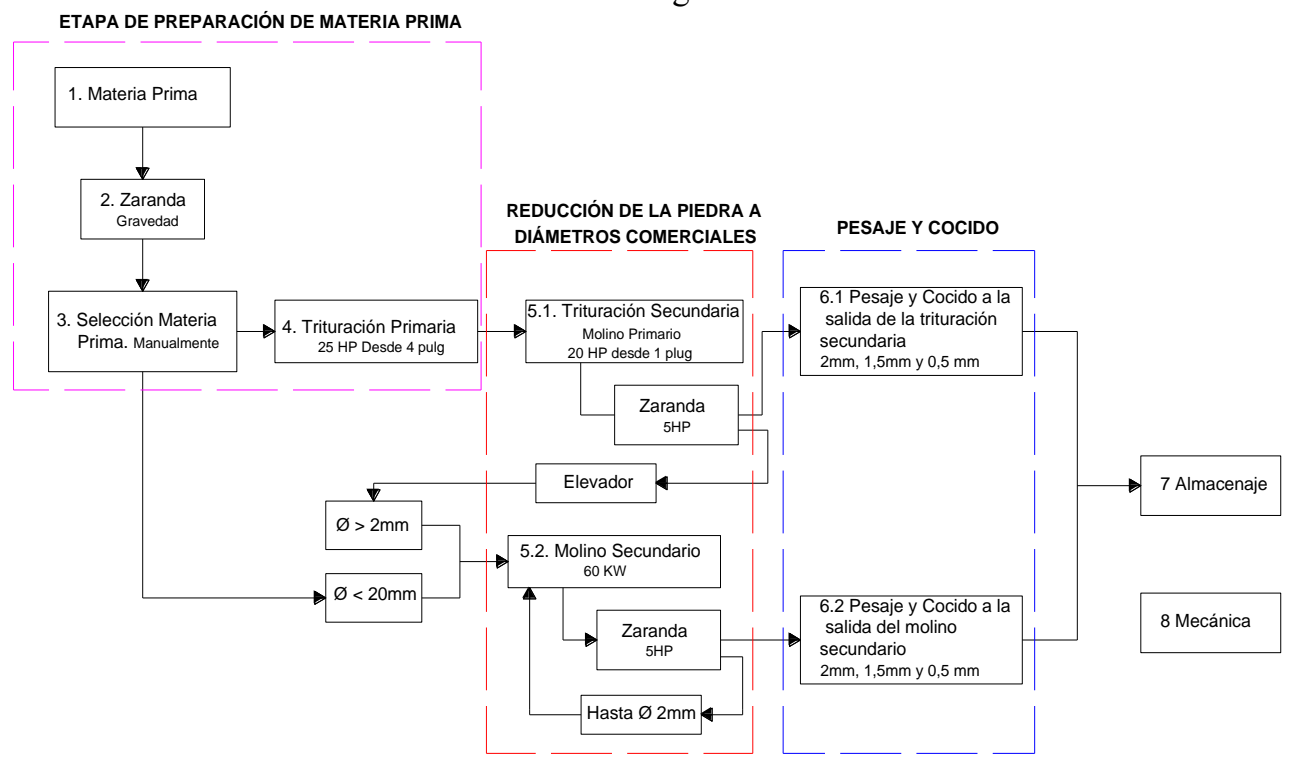

Fuente: Investigación de campo, 2015

Realizado por: Investigadores 
Se elaboró una matriz de riego químico (polvo inorgánico) en las diferentes actividades del proceso de producción de material abrasivo. Cabe mencionar que se obtuvieron riesgos intolerables en las actividades que se muestran a continuación:

Cuadro 1: Riesgos intolerables al polvo identificados en la matriz de riesgos

\begin{tabular}{|c|c|c|}
\hline \multirow{2}{*}{ PROCESO ANALIZADO } & $\begin{array}{c}\text { ACTIVIDAD DEL } \\
\text { PROCESO }\end{array}$ & $\begin{array}{c}\text { ESTIMACIÓN DEL } \\
\text { RIESGO }\end{array}$ \\
\hline \multirow{4}{*}{$\begin{array}{c}\text { ZARANDA DE } \\
\text { GRAVEDAD }\end{array}$} & $\begin{array}{c}\text { Palear el material menor a } \\
1 \text { pulg (detrás de la } \\
\text { zaranda) }\end{array}$ & \multirow{2}{*}{} \\
\cline { 2 - 2 } & $\begin{array}{c}\text { Palear el material mayor a } \\
1 \text { pulg (delante de la } \\
\text { zaranda) }\end{array}$ & \\
\hline TRITURADORA & $\begin{array}{c}\text { Llevar en carretillas el } \\
\text { material mayor a 1 pulg al } \\
\text { molinos secundario }\end{array}$ & \multirow{2}{*}{ Riesgo Intolerable } \\
\cline { 2 - 2 } PRIMARIA & $\begin{array}{c}\text { Palear el material mayor a } \\
1 \text { pulg }\end{array}$ \\
\hline MOLINO SECUNDARIO & $\begin{array}{c}\text { Seleccionar que no se } \\
\text { pasen impurezas }\end{array}$ \\
\hline
\end{tabular}

Fuente: Investigación de campo, 2015

Realizado por: Investigadores

Se caracterizaron las variables de estudio que ayudaron a realizar una escueta higiénica según lo recomienda Falagán et al. (2000),

Gráfico No. 03. Ciclo tecnológico del material abrasivo

VARIA BLE INDEPENDIENTES

- PROCESO PRODUCTIVO

- CICLO TECNOLÓGICO

- ORGANIZACIÓN DEL TRABAJO

- CONDICIONES DEL TRABAJO

- MEDIO AMBIENTE DE TRABAJO

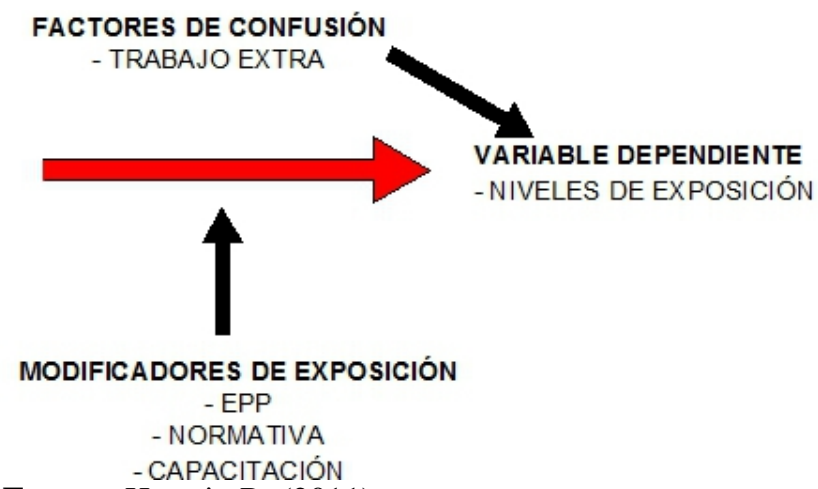

Fuente: Harari, R. (2011)

\section{Caracterización del material particualado}

Debido a la imposibilidad de adquirir equipos para realizar los muestreos se recurrió a una empresa acreditada por el SAE (Servicio de Acreditación Ecuatoriano) denominada CESTTA (Centro de Servicios Técnicos y Transferencia Tecnológica Ambiental). 
Se trabajó en base a la norma NIOSH 0500 para particulado total y NIOSH 0600 para particulado respirable, siendo el procedimiento para las normas el siguiente:

\section{Preparación de muestras antes del muestreo}

1. Equilibrar los filtros en un área de pesaje de ambiente controlado o cámara durante al menos $2 \mathrm{~h}$.

2. Pesar los filtros en una zona de ambiente controlado o cámara. Anotar el peso de tara filtro en (mg).

a. Enserar la microbalanza antes de cada pesada.

b. Maneje el filtro con pinzas.

3. Montar los filtros en los cassettes y cerrar firmemente para que no se produzca fugas alrededor del filtro. Coloque un tapón en cada apertura del cartucho del filtro.

"A los casetes se les deben colocar los dos tapones uno a la entrada del aire (azul) y otro a la salida del aire (rojo)."

Gráfico No. 04. Ensamble para portafiltros de dos cuerpos

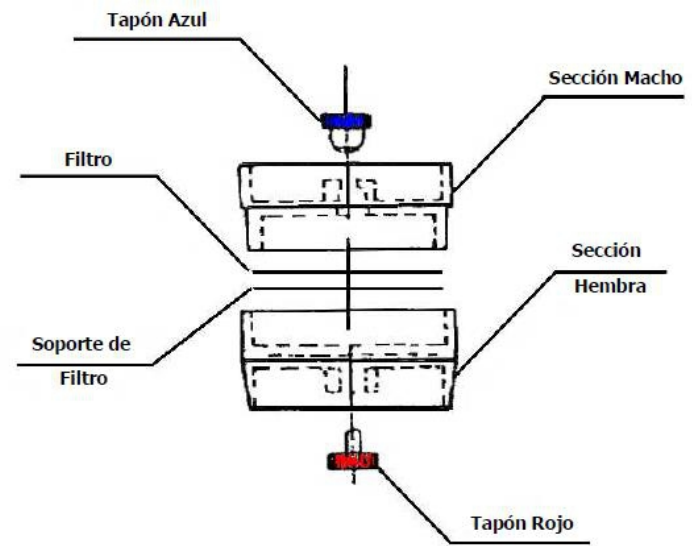

Fuente: Reglamento Técnico Polvo de Sílice (2008)

4. Cuando deba utilizarse ciclón, éste previamente deberá ser desmontado e inspeccionado meticulosamente en su interior.

Suele ser habitual encontrar restos de polvo de mediciones anteriores, por lo que es necesario limpiarlos previamente.

5. Monte el ciclón dependiendo si es para polvo total o respirable. Compruebe la alineación del soporte del filtro y el ciclón en la cabeza de muestreo para evitar fugas.

\section{Muestreo}

6. Calibrar cada bomba de muestreo personal a la velocidad de flujo apropiada NIOSH $05001 \mathrm{~L} / \mathrm{m}$ por 2 horas y NIOSH 0600 2,6 L/m por dos horas y media, No se podrá iniciar la medición si no se tiene la seguridad de 
que la batería está totalmente cargada y que tendrá capacidad para medir durante todo el tiempo previsto.

\section{Preparación de la muestra}

8. Quite los tapones superior e inferior del cassette de filtro. Equilibrar durante al menos $2 \mathrm{~h}$ en un área o cámara de ambiente controlado.

\section{Calibración y control de calidad}

9. Encere la microbalanza (precisión de 0,001 mg) antes de todas las pesadas. Utilice la misma microbalanza para el pesaje de filtros antes y después de la recogida de muestras.

10. Al equilibrar el filtro antes y después de la medición en una cámara de ambiente controlado se asegura que tengas las mismas condiciones.

\section{Medición}

10. Pese cada filtro, incluyendo blancos de campo. Registre este peso después de la toma de muestras (mg).

La cantidad de material particulado retenido en el elemento de retención, expresado en miligramos $(\mathrm{mg})$, se obtiene como diferencia entre la pesada del elemento de retención antes y después del muestreo.

A partir de dicha cantidad, y teniendo en cuenta el volumen de aire muestreado, se obtiene la concentración de material particulado en el aire, en miligramos por metro cúbico.

\section{Descripción del equipo de muestreo}

En el trabajo de campo se utilizó una bomba de muestreo CASELLA

\section{CEL TUF I.S.}

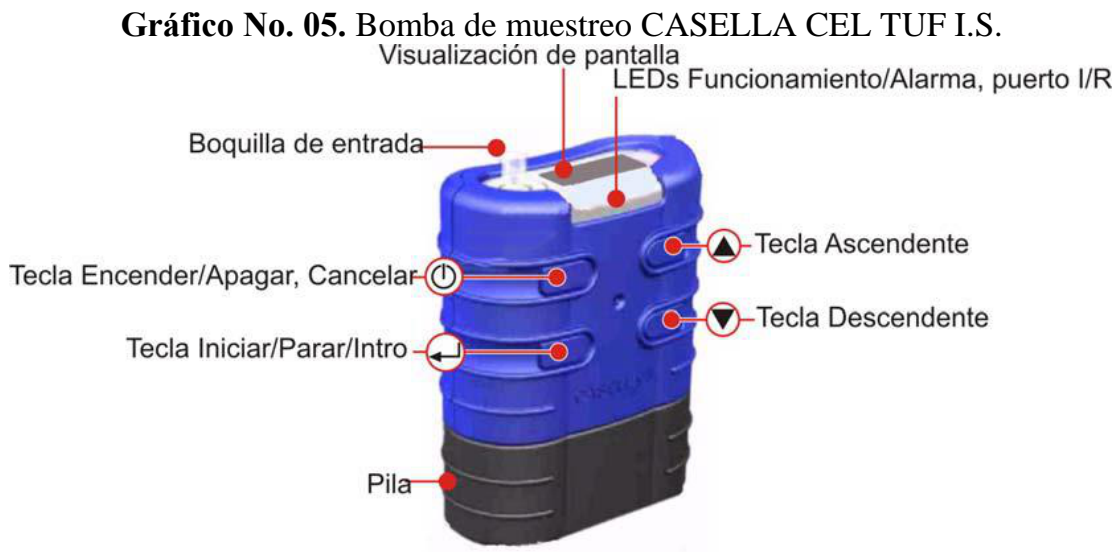

Fuente: Manual del operario HB3343-03 


\section{Medios de retención}

Se utilizó un filtro SKC-225-8-01 que es una membrana de cloruro de polivinilo (PVC), de $37 \mathrm{~mm}$ de diámetro de 2 a 5 micrómetros de tamaños de poros en una casette de dos cuerpos, con sus respectivas tapas de seguridad para cada punto de muestreo.

Gráfico No. 06. Filtro de muestreo y cassette de dos cuerpos.

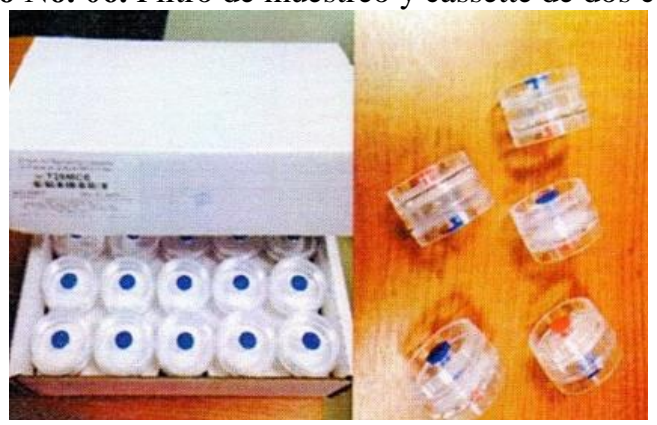

Fuente: CESTTA, 2015

Los ciclones utilizados son dispositivos de aluminio que posee una entrada de aire en sentido transversal.

Gráfico No. 07. Ciclón para fracción de polvo respirable.

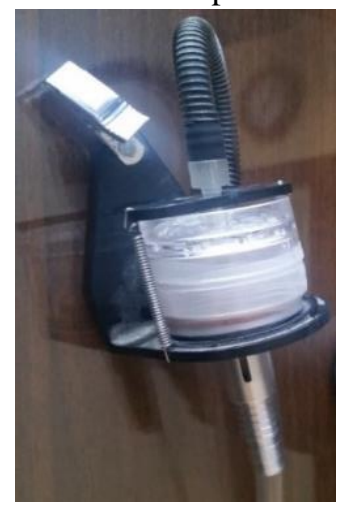

Gráfico No. 08. Ciclón para fracción de polvo total.

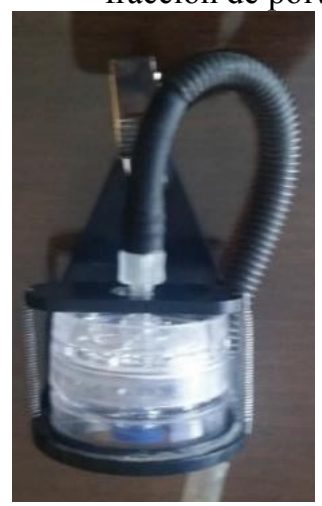

Fuente: Investigación de campo, 2015

Realizado por: Investigadores

En el laboratorio la sensibilidad de la balanza analítica debe ser de $0,01 \mathrm{mg}(0,00001 \mathrm{~g})$, la cámara de pesado debe estar diseñada para mantener un ambiente controlado y se debe disponer de un desecador de vidrio para condicionar los filtros. 
Gráfico No. 09. Área de pesaje y desecador de vidrio

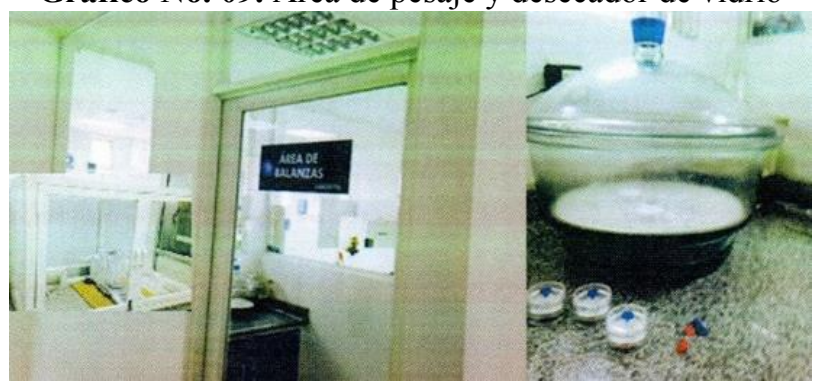

Fuente: CESTTA, 2015

De forma previa a la toma de muestras se realizó in situ una verificación de las baterías de la bomba una preparación de los medios de retención, es decir: desecar los filtros incluido los blancos, pesada de filtros, montaje de los filtros en el portafiltro, sellar y rotular, ubicar el ciclón seleccionador de tamaño de polvo y luego el filtro de recolección para finalmente realizar la secada y el pesaje, donde las condiciones del trabajo fueron óptimas.

\section{Selección De Los Trabajadores A Muestrear}

En la empresa laboran 15 trabajadores en el área de producción $(\mathrm{N}=$ $15)$.

Para encontrar el número de trabajadores [7] que se deberían muestrear se puede proceder de la siguiente manera:

1. Asumir que el límite del $10 \%$ de trabajadores están altamente expuestos por lo tanto en el presente trabajo suponemos que existen dos (2) trabajadores con la más alta exposición.

2. Se elige un límite de confianza del $90 \%$ lo que significa que existe un $90 \%$ de posibilidad de encontrar en el subgrupo a seleccionar al menos a uno de los trabajadores del grupo del $10 \%$ con más exposición.

3. Como se tiene que el límite de alto riesgo es del $10 \%$ y el límite de confianza es del $90 \%$, del grupo de trabajadores $(\mathrm{N}=15)$, analizando la tabla II, se determina que el número de trabajadores a muestrear es 12.

Cuadro 2: Número de trabajadores a muestrear con un $90 \%$ de probabilidad que se muestree a uno de los que están entre el $10 \%$ de mayor exposición

\begin{tabular}{|l|l|l|l|l|l|l|l|l|l|l|l|l|}
\hline \multicolumn{10}{|c|}{$\Lambda=0,1$ y confianza $0,90 \mathrm{n}=\mathrm{N}$ si N $\leq 7$} \\
\hline Tamaño del grupo $\mathrm{N}$ & 8 & 9 & 10 & $11-12$ & $13-14$ & $15-17$ & $18-20$ & $21-24$ & $25-29$ & $30-37$ & $38-40$ & 50 \\
\hline $\begin{array}{l}\mathrm{N}^{*} \text { de Trabajadores } \\
\text { Necesarios a medir (n) }\end{array}$ & 7 & 8 & 9 & 10 & 11 & 12 & 13 & 14 & 15 & 16 & 17 & 18 \\
\hline
\end{tabular}

Fuente: INSHT (2010) y NIOSH (1994)

4. Se realiza la selección aleatoria de los trabajadores, por lo que los trabajadores a ser evaluados son: $1,7,11,10,8,12,6,9,5,2,3,4$. 
Cuadro 3: Números aleatorios para ser muestreados

\begin{tabular}{|c|c|}
\hline Numero aleatorio & Puesto de trabajo \\
\hline 1 & Supervisor \\
\hline 7 & Pesaje y cocido a la salida de la trituradora secundaria \\
\hline 11 & Molino secundario \\
\hline 10 & Mecánica \\
\hline 8 & Molino secundario \\
\hline 12 & Delante de la zaranda de gravedad \\
\hline 6 & Trituración secundaria \\
\hline 9 & Trituración primaria \\
\hline 5 & Montacargas \\
\hline 2 & Detrás de la zaranda de gravedad \\
\hline 3 & Selección de materia prima \\
\hline 4 &
\end{tabular}

Fuente: Trabajo de campo, 2015

Realizado por: investigadores

Se utiliza el criterio estadístico para la interpretación de las concentraciones en las diferentes áreas de preparación del material abrasivo.

Se señalan las tres categorías para calificar la exposición de un trabajador a determinado contaminante con la utilización de los límites de confianza.

\section{a) Existe una sobreexposicion}

Cuando la exposición media supera el valor límite permisible de la sustancia y el Límite Inferior de Confianza (LIC) también lo supera, existe una posibilidad de un $95 \%$ de que el trabajador se encuentre a una exposición de peligro.

LIC $\geq 1$

\section{b) No habrá sobreexposicion:}

Cuando la exposición media no supera el valor límite permisible de la sustancia y el Límite Superior de Confianza (LSC) tampoco lo supera, existe una posibilidad del $95 \%$ de que el trabajador no tenga una exposición peligrosa.

$\mathrm{LIC} \leq 1$

\section{c) Posible sobreexposicion: en los siguientes casos}

I.Cuando la exposición media no supera el VLP, pero el Límite Superior de Confianza (LSC) si lo supera, no se podrá estar seguro en un $95 \%$ de exposición peligrosa.

II.Si la exposición media supera el VLP, pero el Límite Inferior de Confianza no lo supera; no se puede estar seguro en un $95 \%$ de que exista una exposición peligrosa. 
En estos dos casos existe una incertidumbre y se recomienda tomar muestras adicionales dependiendo de la toxicidad de la sustancia.

Gráfico No. 10. Clasificación de los límites de confianza $L I C \leq 1$ Y $L S C \geq 1$

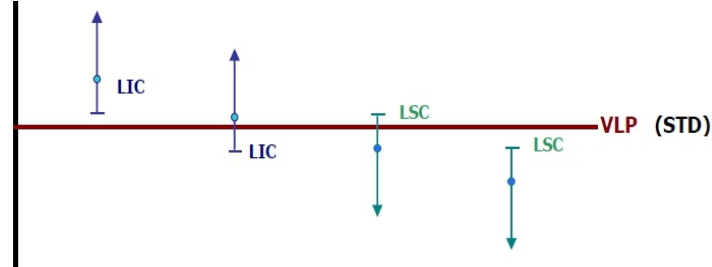

Fuente: Reglamento Técnico Polvo de Sílice (2008)

\section{MUESTREO DE LOS 12 PUNTOS DE MUESTREO}

\section{Comparación del material particulado PM 10}

Gráfico No. 11. Exposición de los puntos muestreados al polvo inhalable

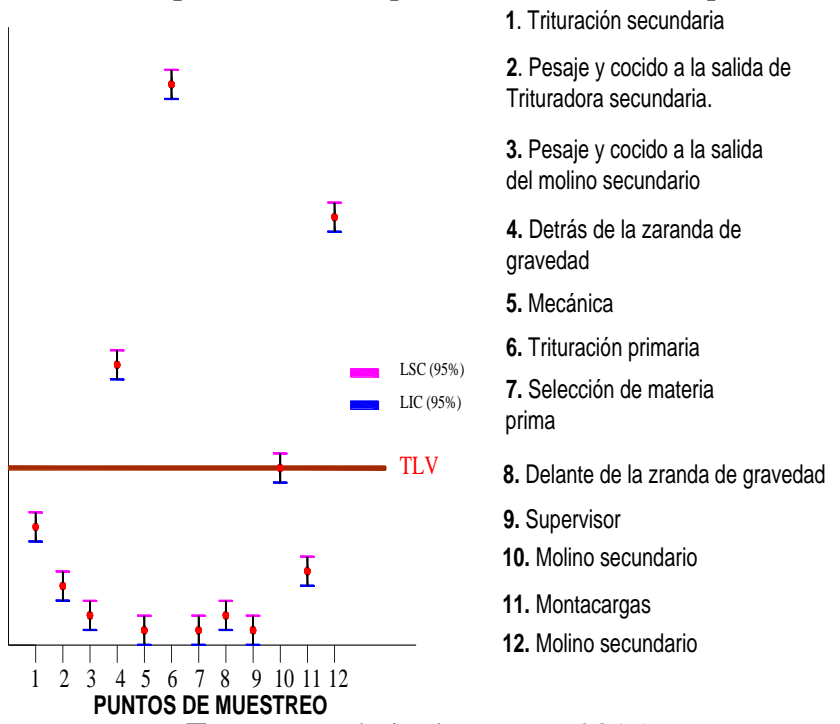

Fuente: Trabajo de campo, 2015

Realizado por: investigadores

\section{Punto de muestreo 4: detrás de la zaranda de gravedad}

Una concentración de PM 10 de $15,83 \mathrm{mg} / \mathrm{m}^{3}$ supera en un 58,3\% al TLV de la norma teniendo una sobreexposición.

\section{Punto de muestreo 6: trituración primaria}

Una concentración de PM 10 de $31,67 \mathrm{mg} / \mathrm{m}^{3}$ supera en un $216,7 \%$ al TLV de la norma teniendo una sobreexposición. Este punto es crítico pero cabe recalcar que la trituradora primaria solamente funciona cuando hay material de más de una pulgada por lo que esta funciona unas dos veces al mes por lo general 4 horas. 
Punto de muestreo 10. Molino secundario

Una concentración de PM 10 de $10 \mathrm{mg} / \mathrm{m}^{3}$ tiene una posible exposición ya que está al límite del TLV de la norma.

\section{Punto de muestreo 12. Molino secundario}

Una concentración de PM 10 de $141,17 \mathrm{mg} / \mathrm{m}^{3}$ supera en un $141,7 \%$ al TLV de la norma teniendo una sobreexposición. La exposición está en función de cómo se envié el material es decir no se acumule a la salida de la zaranda por lo que se presume que en el punto de muestro 10 se mandó poco a poco el material y que en el punto de muestreo 12 se mandó más rápido generándose mucho polvo, siendo este puesto de trabajo critico ya que en las dos mediciones se tiene exposición.

\section{Comparación del material particulado PM 2.5}

Gráfico No. 12. Exposición de los puntos muestreados al polvo respirable

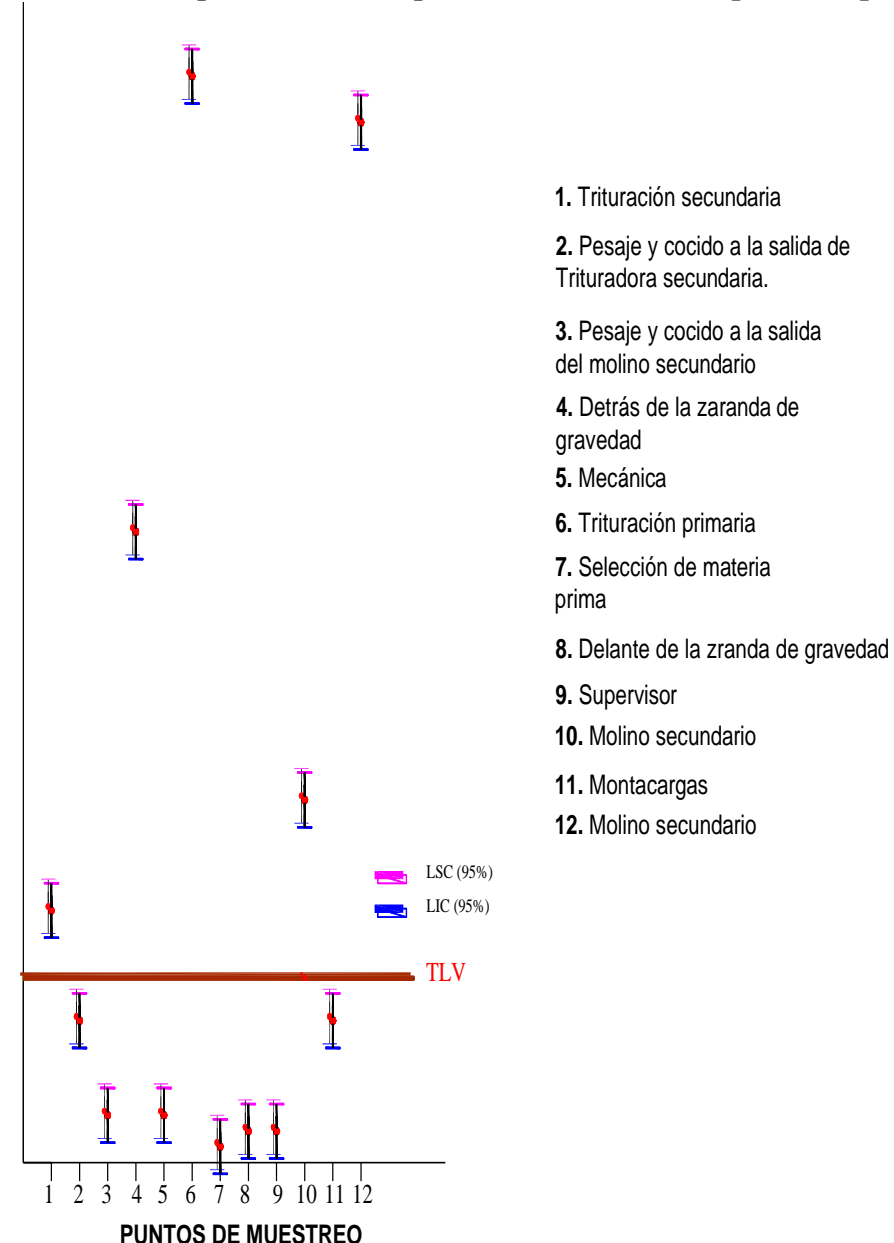

Fuente: Trabajo de campo, 2015

Realizado por: investigadores 


\section{Punto de muestreo 1: trituracion secundaria}

Una concentración de PM 2.5 de $4.1 \mathrm{mg} / \mathrm{m}^{3}$ supera en un $36,6 \%$ el TLV de la norma teniendo una sobreexposición.

No supera el $50 \%$ del límite de exposición, es decir no se deben establecer programas de intervención o mitigación del factor según el reglamento técnico polvo de sílice [7]

El día del muestreo estaba funcionando simultáneamente la trituradora primaria generándose bastante polvo por lo que se pretende que este punto de muestreo resultó con sobreexposición por la presencia de la misma.

La exposición de los siguientes puntos de muestreo son los mismos que para el caso de PM 10 fracción inhalable o total:

\section{Punto 4: detrás de la zaranda de gravedad}

Una concentración de PM 2.5 de $10,26 \mathrm{mg} / \mathrm{m}^{3}$ supera en un $242 \%$ el TLV de la norma teniendo una sobreexposición.

\section{Punto 6: trituración primaria}

Una concentración de PM 2.5 de $17,69 \mathrm{mg} / \mathrm{m}^{3}$ supera en un 489,6\% el TLV de la norma teniendo una sobreexposición.

\section{Punto 10. Molino secundario}

Una concentración de PM 2.5 de $5,9 \mathrm{mg} / \mathrm{m}^{3}$ supera en un $96,6 \%$ el TLV de la norma teniendo una sobreexposición.

\section{Punto 12. Molino secundario}

Una concentración de PM 2.5 de $16,92 \mathrm{mg} / \mathrm{m}^{3}$ supera en un $464 \%$ el TLV de la norma teniendo una sobreexposición.

Se presume que en este punto se envió más rápido el material generándose mucho más polvo.

En 5 puntos muestreados hay exposición para PM 2.5, siendo dos de estos el molino secundario.

\section{Propuesta prelimimar o reducir la exposición al material particulado [2] Acta de compromiso}

En función de las exposiciones obtenidas se elaboró un acta de compromiso ANEXO XXIX para reducir o eliminar la exposición al material particulado generado en los siguientes puestos de trabajo, como se detalla a continuación:

Cuadro 4: Puntos expuestos en el muestreo

\begin{tabular}{|c|c|c|c|c|}
\hline $\begin{array}{c}\text { Punto } \\
\text { muestreado }\end{array}$ & $\begin{array}{c}\text { Polvo } \\
\text { inhalable } \\
\text { NIOSH } 0600\end{array}$ & Observaciones & $\begin{array}{c}\text { Polvo } \\
\text { respirable } \\
\text { NIOSH } 0500\end{array}$ & Observaciones \\
\hline
\end{tabular}




\begin{tabular}{|c|c|c|c|c|}
\hline & $\begin{array}{c}(\mathrm{TLV}=10 \\
\left.\mathrm{mg} / \mathrm{m}^{3}\right)\end{array}$ & & $\begin{array}{c}(\mathrm{TLV}=3 \\
\left.\mathrm{mg} / \mathrm{m}^{3}\right)\end{array}$ & \\
\hline $\begin{array}{l}\text { PUNTO 1: } \\
\text { Trituración } \\
\text { secundaria }\end{array}$ & $6,67 \mathrm{mg} / \mathrm{m}^{3}$ & No hay exposición & $4,10 \mathrm{mg} / \mathrm{m}^{3}$ & $\begin{array}{c}\text { - 36,6\% más de } \\
\text { exposición. } \\
\text { - No supera el } \\
50 \% \text { del límite } \\
\text { permisible. } \\
\text { - Influencia de la } \\
\text { trituradora } \\
\text { primaria. } \\
\text { - Se va a volver a } \\
\text { evaluar sin la } \\
\text { influencia de la } \\
\text { trituradora } \\
\text { primaria. }\end{array}$ \\
\hline $\begin{array}{c}\text { PUNTO 4: } \\
\text { Detrás de la } \\
\text { zaranda }\end{array}$ & $15,83 \mathrm{mg} / \mathrm{m}^{3}$ & $\begin{array}{l}58,3 \% \text { más de } \\
\text { exposición }\end{array}$ & $10,26 \mathrm{mg} / \mathrm{m}^{3}$ & $\begin{array}{l}242 \% \text { más de } \\
\text { exposición. }\end{array}$ \\
\hline $\begin{array}{c}\text { PUNTO 6: } \\
\text { Trituración } \\
\text { primaria }\end{array}$ & $31,67 \mathrm{mg} / \mathrm{m}^{3}$ & $\begin{array}{c}216,7 \% \text { más de } \\
\text { exposición }\end{array}$ & $17,69 \mathrm{mg} / \mathrm{m}^{3}$ & $\begin{array}{l}\text { 489,6\% más de } \\
\text { exposición. }\end{array}$ \\
\hline $\begin{array}{c}\text { PUNTO 10: } \\
\text { Molino } \\
\text { secundario }\end{array}$ & $10 \mathrm{mg} / \mathrm{m}^{3}$ & $\begin{array}{c}\text { Posible } \\
\text { sobreexposición. } \\
\text { No supera el } 50 \% \\
\text { del límite } \\
\text { permisible. }\end{array}$ & $5,9 \mathrm{mg} / \mathrm{m}^{3}$ & $\begin{array}{l}\text { 96,6\% más de } \\
\text { exposición. }\end{array}$ \\
\hline $\begin{array}{c}\text { PUNTO 12: } \\
\text { Molino } \\
\text { secundario }\end{array}$ & $24,17 \mathrm{mg} / \mathrm{m}^{3}$ & $\begin{array}{c}141,7 \% \text { más de } \\
\text { exposición }\end{array}$ & $16,92 \mathrm{mg} / \mathrm{m}^{3}$ & $\begin{array}{l}464 \% \text { más de } \\
\text { exposición. }\end{array}$ \\
\hline
\end{tabular}

Fuente: Trabajo de campo, 2015

Realizado por: investigadores

\section{Medidas técnicas de prevención a implementar conforme al acta de compromiso}

En el acta se establece que se va actuar en el punto de muestreo 4 y 6 desde el punto de vista:

a) Organizativo: Cambiar la posición del trabajador en estos puestos de trabajo. En el momento que está funcionando la trituradora primaria y la zaranda de gravedad, deben retirarse hasta que el montacargas deposite el material, dejando que el polvo baje hasta el nivel del piso para volver al puesto de trabajo, esto tomará de 3 a 5 minutos tiempo en que el montacargas regresará a proveerse de más material.

b) Formación e información sobre técnica preventivas: capacitando al personal de producción sobre la forma adecuada de prevenir la inhalación de polvo. 


\section{Medidas de protección colectivas a implementar conforme al acta de compromiso}

Extracción localizada: Los punto de muestreo 10 y 12 que corresponde al molino secundario son los más críticos del estudio y por ello se va implementar una extracción localizada funcionando en el momento que se encienda el molino secundario y aislando al trabajador del polvo.

Gráfico No. 13. Campana extractora en el puesto del trabajador en el molino secundario

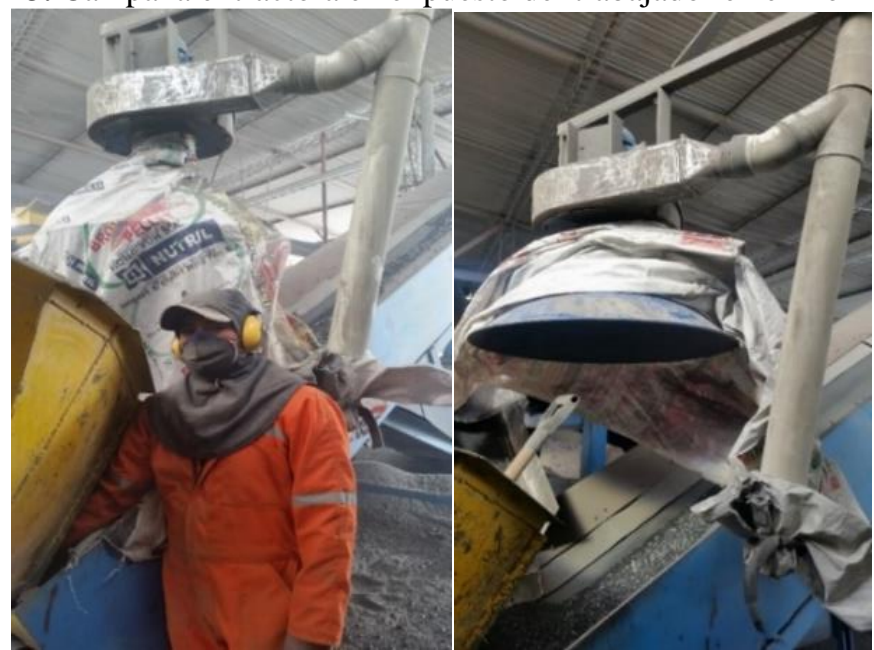

Fuente: Trabajo de campo, 2015

Realizado por: investigadores

Una vez implementadas estas acciones correctivas se volvieron a muestrear los puntos 1, 4, 6, 10 y 12 para realizar las comparaciones y verificar si el nivel de exposición disminuyó.

También se ha establecido que todos los lunes de 8 a 12 se haga una limpieza del polvo depositado sobre suelos, estructuras y máquinas, para evitar que éste se acumule y pueda influir en la exposición del trabajador.

\section{Medidas de protección individual}

Con respecto a esta medida de protección, a pesar de que no consta en el acta de compromiso se recomendó el uso de respiradores para partículas $\underline{3 \mathrm{M}^{\mathrm{TM}} 8511 \mathrm{~N} 95 \text { para todos los trabajadores de la empresa. }}$ 


\section{Comparación del material particulado PM 10 con acciones correctivas}

Gráfico No. 14. Exposición de los puntos muestreados al polvo inhalable con acciones correctivas

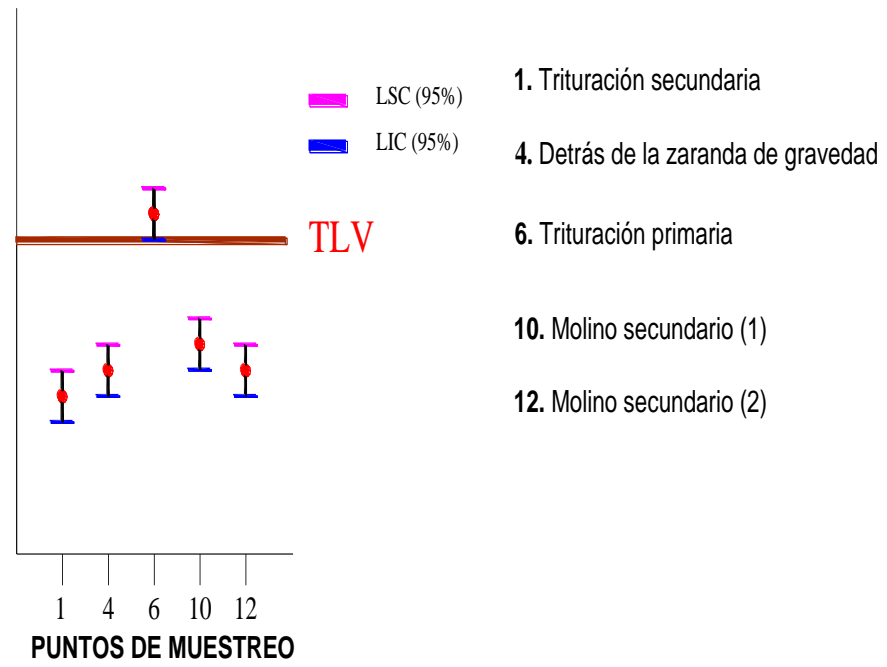

Fuente: Trabajo de campo, 2015

Realizado por: investigadores

De acuerdo al criterio estadístico se tiene un solo punto con posible exposición:

\section{Punto 6: trituración primaria.}

Una concentración de PM 10 de $10,83 \mathrm{mg} / \mathrm{m}^{3}$ supera en un $8,3 \%$ el TLV de la norma donde anteriormente se tuvo $216,7 \%$ de sobrexposición.

Como la exposición no supera el 50\% del límite de exposición no se deben establecer programas de intervención o mitigación del factor según el reglamento técnico polvo de sílice (2008) [7]

El cambio en el proceso organizativo del puesto de trabajo influyó significativamente en la exposición del trabajador. 


\section{Comparación del material particulado PM 2.5}

Gráfico No. 15. Exposición de los puntos muestreados al polvo respirable con acciones correctivas

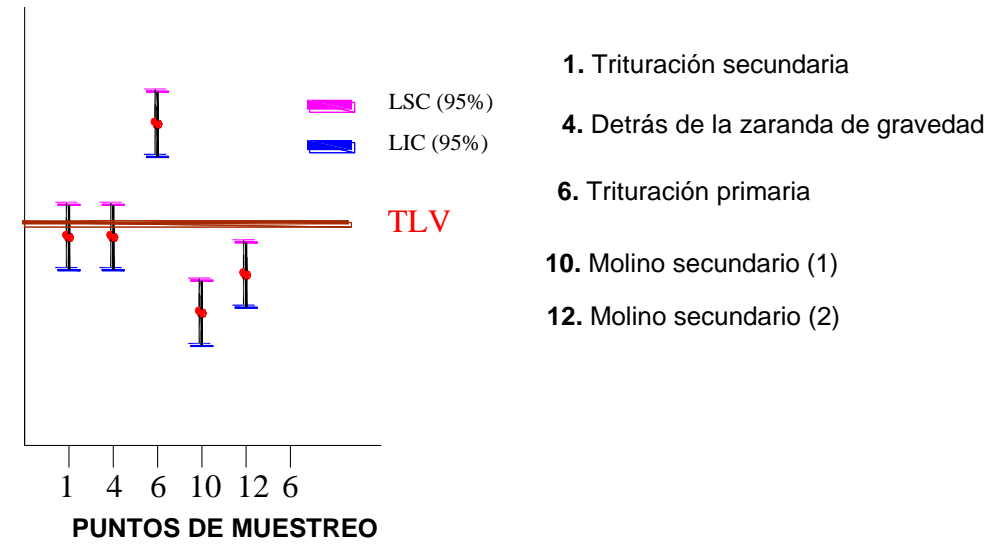

Fuente: Trabajo de campo, 2015

Realizado por: investigadores

De acuerdo al criterio estadístico se tienen los puestos que tienen sobreexposición y posible exposición:

\section{Punto 1: trituracion secundaria}

Una concentración de PM 2.5 de $2,82 \mathrm{mg} / \mathrm{m}^{3}$ no supera el TLV de la norma.

Tiene una posible exposición, porque el límite superior de confiabilidad supera en un $8,8 \%$ del TLV, sin embargo la concentración obtenida no lo supera, por lo que se estaría trabajando a un 94\% del TLV de la norma.

\section{Punto 4: detrás de la zaranda de gravedad}

Una concentración de PM 2.5 de $2,82 \mathrm{mg} / \mathrm{m}^{3}$ no supera el TLV de la norma.

Al igual que el punto anterior se estaría trabajando a un 94\% del TLV, mientras que en la anterior medición se obtuvo una sobreexposición de $242 \%$ de exposición.

El cambio en el proceso organizativo del puesto de trabajo influyó significativamente en la exposición del trabajador.

\section{Punto 6: trituración primaria}

Una concentración de PM 2.5 de $4,36 \mathrm{mg} / \mathrm{m}^{3}$ supera en un 45,3 el TLV de la norma, donde anteriormente se tuvo 489,6\% de sobreexposición.

El cambio en el proceso organizativo del puesto de trabajo influyó significativamente en la exposición del trabajador. 
La exposición en los puntos 1, 4 y 6 no superan el 50\% del límite de exposición no se deben establecer programas de intervención o mitigación del factor según el reglamento técnico polvo de sílice (2008).

\section{Comparación de las concentraciones de los puntos expuestos antes y después de las acciones correctivas}

Cuadro 5: Comparación de exposiciones ates y después de las acciones correctivas

\begin{tabular}{|c|c|c|c|c|c|}
\hline & \multicolumn{2}{|c|}{ PUNTOS EXPUESTOS } & \multicolumn{3}{|c|}{$\begin{array}{l}\text { PUNTOS EXPUESTOS CON } \\
\text { ACCIONES CORRECTIVAS }\end{array}$} \\
\hline $\begin{array}{c}\text { Punto } \\
\text { muestreado }\end{array}$ & $\begin{array}{c}\text { Polvo } \\
\text { inhalable } \\
\text { NIOSH } \\
0600 \\
(\mathrm{TLV}=10 \\
\left.\mathbf{m g} / \mathbf{m}^{3}\right)\end{array}$ & $\begin{array}{c}\text { Polvo } \\
\text { respirable } \\
\text { NIOSH } \\
0500 \\
(\mathrm{TLV}=\mathbf{3} \\
\left.\mathbf{m g} / \mathbf{m}^{3}\right)\end{array}$ & $\begin{array}{c}\text { Polvo } \\
\text { inhalable } \\
\text { NIOSH } \\
\text { 0600 } \\
(\mathrm{TLV}=10 \\
\left.\mathrm{mg} / \mathrm{m}^{3}\right)\end{array}$ & $\begin{array}{c}\text { Polvo } \\
\text { respirable } \\
\text { NIOSH } \\
0500 \\
(\mathrm{TLV}=\mathbf{3} \\
\left.\mathbf{m g} / \mathbf{m}^{\mathbf{3}}\right)\end{array}$ & Observaciones \\
\hline $\begin{array}{l}\text { PUNTO 1: } \\
\text { Trituración } \\
\text { secundaria }\end{array}$ & $6,67 \mathrm{mg} / \mathrm{m}^{3}$ & $4,10 \mathrm{mg} / \mathrm{m}^{3}$ & $5 \mathrm{mg} / \mathrm{m}^{3}$ & $\begin{array}{c}2,82 \\
\mathrm{mg} / \mathrm{m}^{3}\end{array}$ & $\begin{array}{c}\text { Cumple las } \\
\text { normas } \\
\text { NO HAY } \\
\text { exposición }\end{array}$ \\
\hline $\begin{array}{c}\text { PUNTO 4: } \\
\text { Detrás de la } \\
\text { zaranda }\end{array}$ & $\begin{array}{c}15,83 \\
\mathrm{mg} / \mathrm{m}^{3}\end{array}$ & $\begin{array}{c}10,26 \\
\mathrm{mg} / \mathrm{m}^{3}\end{array}$ & $5,83 \mathrm{mg} / \mathrm{m}^{3}$ & $\begin{array}{c}2,82 \\
\mathrm{mg} / \mathrm{m}^{3}\end{array}$ & $\begin{array}{c}\text { Cumple las } \\
\text { normas } \\
\text { NO HAY } \\
\text { exposición }\end{array}$ \\
\hline $\begin{array}{c}\text { PUNTO 6: } \\
\text { Trituración } \\
\text { primaria }\end{array}$ & $\begin{array}{l}31,67 \\
\mathrm{mg} / \mathrm{m}^{3}\end{array}$ & $\begin{array}{c}17,69 \\
\mathrm{mg} / \mathrm{m}^{3}\end{array}$ & $\begin{array}{c}10,83 \\
\mathrm{mg} / \mathrm{m}^{3}\end{array}$ & $\begin{array}{c}4,36 \\
\mathrm{mg} / \mathrm{m}^{3}\end{array}$ & $\begin{array}{l}\text { Existe } \\
\text { exposición }\end{array}$ \\
\hline $\begin{array}{l}\text { PUNTO 10: } \\
\text { Molino } \\
\text { secundario }\end{array}$ & $10 \mathrm{mg} / \mathrm{m}^{3}$ & $5,9 \mathrm{mg} / \mathrm{m}^{3}$ & $6,67 \mathrm{mg} / \mathrm{m}^{3}$ & $\begin{array}{c}1,79 \\
\mathrm{mg} / \mathrm{m}^{3}\end{array}$ & $\begin{array}{c}\text { Cumple las } \\
\text { normas } \\
\text { NO HAY } \\
\text { exposición }\end{array}$ \\
\hline $\begin{array}{l}\text { PUNTO 12: } \\
\text { Molino } \\
\text { secundario }\end{array}$ & $24,17 \mathrm{mg} / \mathrm{m}^{3}$ & $16,92 \mathrm{mg} / \mathrm{m}^{3}$ & $5,83 \mathrm{mg} / \mathrm{m}^{3}$ & $\begin{array}{c}2,31 \\
\mathrm{mg} / \mathrm{m}^{3}\end{array}$ & $\begin{array}{c}\text { Cumple las } \\
\text { normas } \\
\text { NO HAY } \\
\text { exposición }\end{array}$ \\
\hline
\end{tabular}

Fuente: Trabajo de campo, 2015

Realizado por: investigadores

Como se observa las acciones correctivas establecidas en el acta de compromiso ayudaron significativamente a minimizar la exposición. Sin embargo la trituradora primaria sigue siendo un puesto donde persiste la exposición al material particulado tanto para polvo total como respirable. Se debe destacar que funciona de una a dos veces por mes durante cuatro horas por lo que el trabajador no estaría expuesto siempre a este puesto de trabajo y además si se considera que entre ellos se rotan en los puestos de trabajo no habría exposición.

Adicionalmente se plantearán medidas de prevención adicionales que ayuden a disminuir la exposición al polvo, generando un ambiente de trabajo 
más limpio a más de las acciones correctivas establecidas en el acta de compromiso.

\section{Medidas de prevención adicionales}

Cabe indicar que se han hecho algunas acciones como:

Limpieza: El polvo depositado sobre suelos, estructuras y maquinarias es limpiado todos los lunes 8 a 12 del día para evitar que este se acumule y pueda influir en la exposición del trabajador.

Control médico: Como toda persona que trabaja en procesos donde existe polvo debe tener un control periódico por lo que en la empresa se realizaron espirometrías a todos los trabajadores las cuales fueron comparados con los puntos de estudio y se tiene:

Cuadro 6: Espirometrías realizadas en los diferentes puestos de trabajo

Fuente: Empresa en estudio

\begin{tabular}{|c|c|c|c|}
\hline PUNTO & PUESTO DE TRABAJO & ESPIROMTRIA & RESULTADO \\
\hline 1 & Trituradora Secundaria & Sí & $\begin{array}{l}\text { Espirometría } \\
\text { Normal }\end{array}$ \\
\hline 2 & $\begin{array}{c}\text { Pesaje y cocido a la salida de la } \\
\text { trituradora secundaria }\end{array}$ & Sí & $\begin{array}{l}\text { Espirometría } \\
\text { Normal }\end{array}$ \\
\hline 3 & $\begin{array}{l}\text { Pesaje y cocido a la salida del } \\
\text { molino secundario }\end{array}$ & No & ------- \\
\hline 4 & Detrás de la zaranda de gravedad & Sí & $\begin{array}{l}\text { Espirometría } \\
\text { Normal }\end{array}$ \\
\hline 5 & Mecánica & Sí & $\begin{array}{l}\text { Espirometría } \\
\text { Normal } \\
\end{array}$ \\
\hline 6 & Trituradora primaria & $\mathrm{Si}$ & $\begin{array}{l}\text { Espirometría } \\
\text { Normal }\end{array}$ \\
\hline 7 & Selección de materia prima & Sí & $\begin{array}{l}\text { Espirometría } \\
\text { Normal }\end{array}$ \\
\hline 8 & $\begin{array}{c}\text { Delante de la zaranda de } \\
\text { gravedad }\end{array}$ & No & $\begin{array}{ll}------ \\
--1\end{array}$ \\
\hline 9 & Supervisor & Sí & $\begin{array}{l}\text { Espirometría } \\
\text { Normal }\end{array}$ \\
\hline 10 & Molino secundario & Sí & $\begin{array}{l}\text { Espirometría } \\
\text { Normal }\end{array}$ \\
\hline 11 & Montacargas & Sí & $\begin{array}{l}\text { Espirometría } \\
\text { Normal }\end{array}$ \\
\hline \multirow[t]{4}{*}{12} & Molino secundario & Sí & $\begin{array}{l}\text { Espirometría } \\
\text { Normal }\end{array}$ \\
\hline & Mecánica & Sí & $\begin{array}{l}\text { Espirometría } \\
\text { Normal }\end{array}$ \\
\hline & Trituradora secundaria & Sí & $\begin{array}{l}\text { Espirometría } \\
\text { Normal }\end{array}$ \\
\hline & Pesaje y cocido & Sí & $\begin{array}{l}\text { Espirometría } \\
\text { Normal }\end{array}$ \\
\hline
\end{tabular}

Realizado por: investigadores 
Se propusieron acciones técnicas adicionales que involucran el proceso productivo de transformación del material abrasivo, aprovechando el extractor de polvos que dispone la empresa.

\section{Protección colectiva adicional}

Zaranda de gravedad: Se va a diseñar un encerramiento de la zaranda para cuando el material pase a través de la misma el polvo sea absorbido por el extractor de polvos principal, además tendrá una compuerta para poder sacar las piedras atoradas que quedan por el proceso de cernido.

Gráfico No. 16. Zaranda con extractor de polvo.

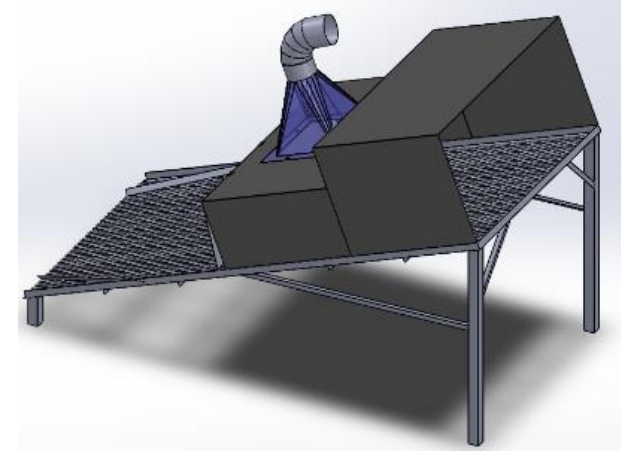

Fuente: Trabajo de campo, 2015

Realizado por: investigadores

Trituradora primaria: Como este puesto es el más crítico en ambas mediciones se va a diseñar un sistema de extracción del polvo conectado en las mandíbulas para que cuando caiga la piedra se absorba la mayor cantidad de polvo.

Gráfico No. 17. Trituradora primaria con extractor de polvo

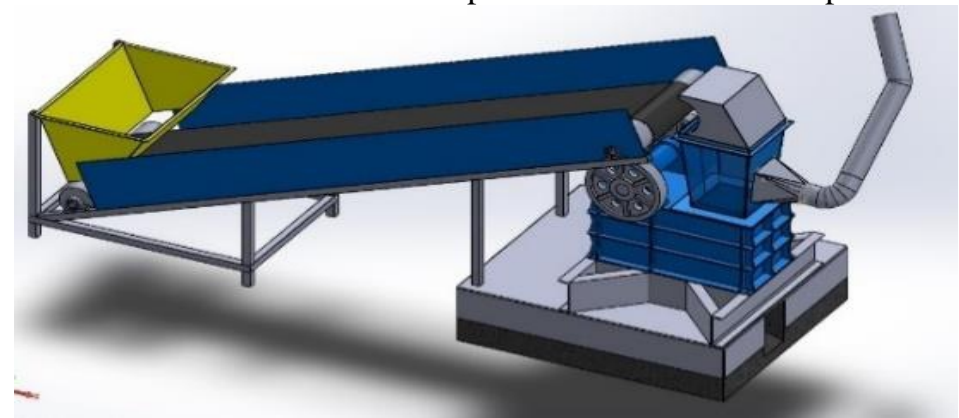

Fuente: Trabajo de campo, 2015

Realizado por: investigadores

El objetivo de la propuesta de implementar extractores de polvo en la trituradora primaria y en la zaranda de gravedad es para ayudar a reducir la exposición al polvo, al igual que se realizó en el molino secundario dando resultados excelentes resultados en las nuevos monitoreos. 
Esto es una implementación que necesita la empresa en bien de la misma y de sus trabajadores.

A continuación se presenta un esquema de cómo quedaría la zaranda de gravedad, la trituradora primaria, el molino secundario conectados al extractor de polvos principal.

Gráfico No. 18. Sistema de extracción de la trituradora primaria, zaranda de gravedad y molino secundario unido al extractor de polvos principal

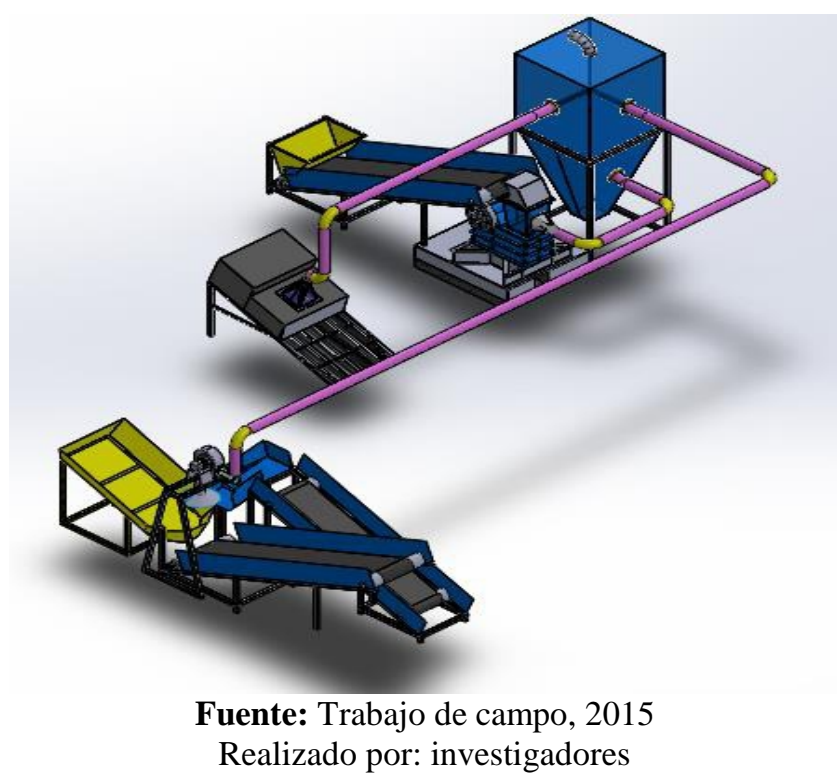

\section{Conclusiones}

En la trituración secundaria y en el punto detrás de la zaranda se está trabajando al límite del TLV para polvo respirable, es decir, en un 94\% después de la acciones correctivas, además también son puntos que se identificaron con riesgo intolerable en la matriz de riesgos, sin embargo este proceso se ve afectado porque trabaja durante toda la jornada laboral simultáneamente con otros procesos.

La trituradora primaria es el punto de muestreo donde más presencia de polvo existe tanto en los muestreos previos y posteriores a las acciones correctivas, como también en los identificados como riesgos intolerables en la matriz de riesgos. Sin embargo este proceso se lo realiza una vez por mes aproximadamente y por cuatro horas por lo que no habría exposición para el trabajador.

En la empresa el 78\% de los trabajadores gana más que el sueldo básico debido a las horas extras que desarrolla durante la semana, siendo los de producción quienes tienen más horas extras y más de 60 horas específicamente los trabajadores del molino secundario ya que este es un proceso que siempre está en funcionamiento. 
En la encuesta el $94 \%$ dice estar expuesto a polvo, $89 \%$ a ruido y el $67 \%$ a vibraciones. Además que el $78 \%$ utiliza mascarilla, el 100\% está consciente de que existe un extractor de polvos principal y que se han hecho acciones para reducir el ruido.

A pesar que la calidad de materia prima es alta, el estado de las maquinarias y de las instalaciones es bueno y se realiza el mantenimiento adecuado EXISTE LA PRESENCIA DE POLVO EN LAS ÁREAS DE PREPARACIÓN DEL MATERIAL ABRASIVO.

Esto se debe a que mientras más seca esté la piedra más se concentra el polvo en la misma; sin embargo para que pueda ser procesada en las diferentes áreas de producción debe estar en estas condiciones y de esta manera el polvo que contiene caiga, así la arena que se obtiene vaya sin polvo ya que este daña la calidad del producto que se comercializa.

Se puede mejorar el ambiente de trabajo si se conectan todos los procesos al extractor de polvo principal ayudando a proteger a los trabajadores de la exposición, como se realizó con el extractor que se implementó en el molino secundario.

\section{References:}

1. Alessio, F. (1ra ed.).(2002). Administración y dirección de la producción: Enfoque estratégico y de Calidad. Bogotá D.C.: Pearson Educación de Colombia Ltda.

2. Asociación Chilena de Seguridad, ACHS. (2001). Decreto Supremo Nro 594. Sobre Condiciones Sanitarias y Ambientales Básicas en los lugares de trabajo. Chile.

3. Banderas, F. (2013). Informe Técnico científico de Dióxido de Silicio. Riobamba.

4. Bossi, J., Ortiz, A., Caggiano, R., Olveira, C. (2011). Manual Didáctico de Geología para estudiantes de Agronomía. Uruguay: Ucur.

5. Falagán, M., Alonso, A., Piñol, P., \& Fernández, J. (1 ${ }^{\text {ra }}$ ed.). (2000). Manual de Prevención de Riesgos Laborales: Higiene Industrial, Seguridad y Ergonomía. Oviedo, España: Copyright.

6. Cortez, J. M. (9na ed.). (2007). Seguridad e Higiene en el Trabajo: Técnicas de Precaución de Riesgos Laborales. Tebar.

7. Decreto Supremo Nro. 594 del ministerio de Salud (Asociación Chilena de Seguridad, ACHS. 2001). 
8. Harari, R. (2007). Exposición al polvo mineral y Efectos sobre la función Respiratoria. Revista Ambiente y salud.

9. Harari, R. (2011). El estudio de la salud en el trabajo en el Ecuador. Revista Eídos, (4), $31-37$.

10. Instituto Nacional de Seguridad e Higiene en el Trabajo, INSHT. (2013). Límites de exposición Profesional para Agentes Químicos en España.

11. Netse (s.f.). Determinación de las concentraciones de exposición laboral a sílice cristalina y polvo no clasificado fracción respirable en los diferentes puestos de trabajo en la construcción de edificios de altura. Proyecto de Investigación y Desarrollo de la prevención y protección de los Riesgos Laborales

12. NIOSH. Industrial Hygiene Sampling. Decision Making Monitoring and Recordkeeping Sampling Strategies. 553. Ohio. (1980).

13. NIOSH. (4 ${ }^{\text {ta }}$ ed.). Manual of Analytical Methods. (1994).

14. NIOSH 0500: Método de determinación de particulado total. (1994)

15. NIOSH 0600: Métodos de determinación de particulado respirable. (1998)

16. OMS. (2005). Guías de calidad del aire de la OMS relativas al material particulado, el ozono, el dióxido de nitrógeno y el dióxido de azufre, Actualización mundial 2005. Resumen de evaluación de riesgos. Organización Mundial de la Salud.

17. Querol. J. (2008). El Material Particulado Atmosférico. Congreso Nacional del Medio Ambiente 8. 1 - 28.

18. (Shiavon, Redondo, \& Yoshida, 2007)

19. Reglamento Técnico Polvo de Sílice. (2008). Ministerio de Trabajo y Seguridad Social con Universidad de Quindío: Colombia.

20. Simancas, A. I.; Cubero, S.; Delgado, J.F.; Sastre, V.; García, A.; Hita, F.; Fernández, F.J.; García, M. (2011). Campaña de control del polvo y la sílice libre cristalina en el sector de ladrillos y tejas de arcilla cocida. Guía de buenas prácticas para el control del polvo y la sílice cristalina en el sector de los ladrillos y tejas de arcilla cocida

21. Schiavon, M., Redondo, S., \& Yoshida, I. (2007). Thermal and morphological characterization of basalt continuous fibers. Cerámica, 53. 